\title{
Leisure-Time Physical Activity is Associated with reduced Risk of Breast Cancer and Triple Negative Breast Cancer in Nigerian Women: a matched case-control study
}

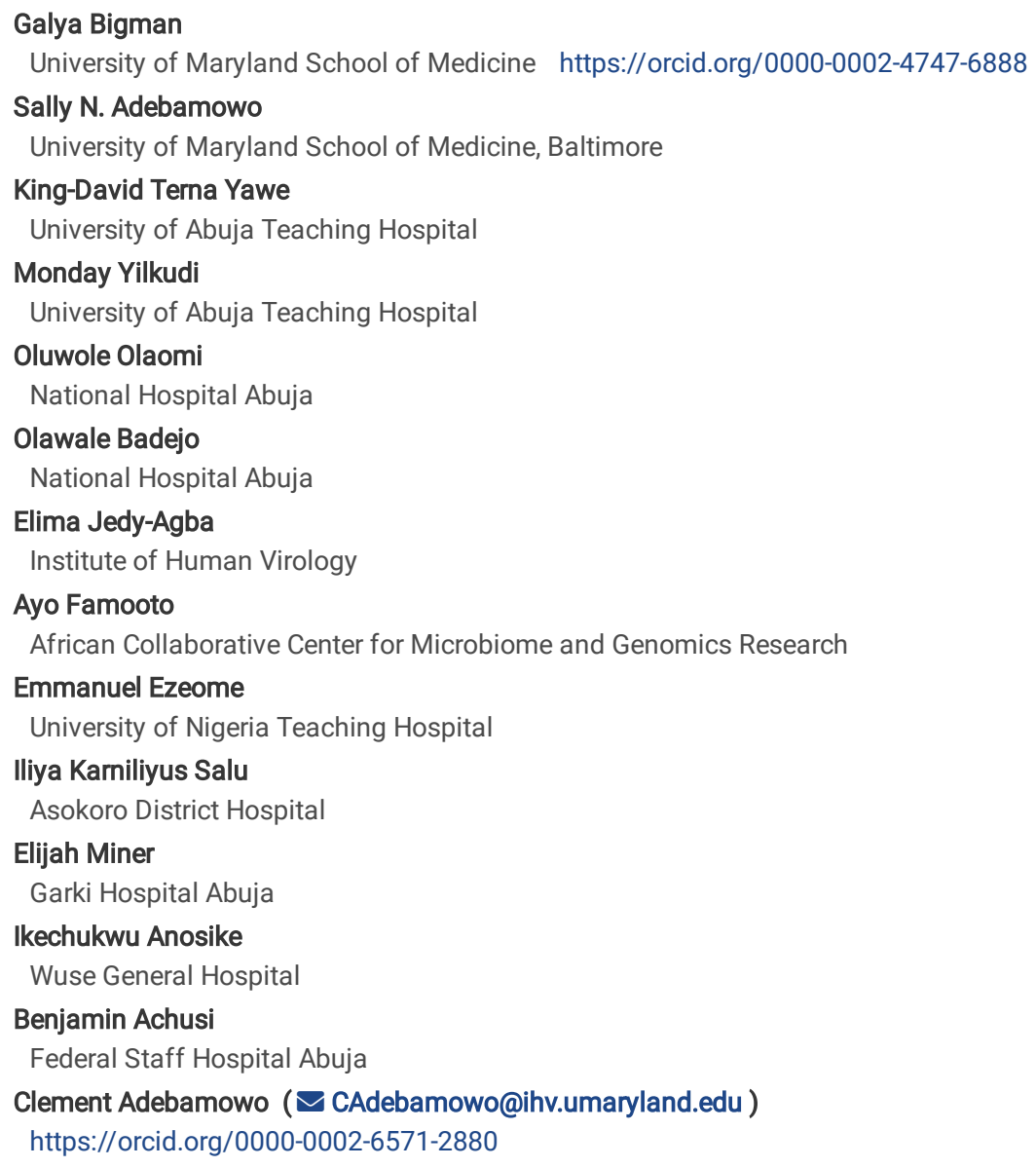




\section{Abstract}

Background Physical activity is associated with reduced risk of breast cancer and its various subtypes but this association is less known in African women, particularly with triple-negative breast cancer that occurs more frequently in Sub-Saharan Africa compared to developed countries. In this study, we examined the association between leisure-time physical activity (LTPA) and breast cancer in total and by its subtypes in Nigerian women. Methods Overall, 630 newly diagnosed patients with primary invasive breast cancer were age-matched ( $\pm 5 y$ ears) with 630 controls from the Nigerian Integrative Epidemiology of Breast Cancer (NIBBLE) Study from 01/2014-07/2016. We derived the average amount of time spent on LTPA per week over the past year using a modified Nurses' Health Study-II physical activity questionnaire. We calculated the total metabolic equivalents (METs) for each reported LTPA per hour/week (i.e. walking, cycling, and dancing) and compared odds of breast cancer among participants who attained the World Health Organization (WHO) physical activity(PA) recommendations of at least 150 minutes of moderate-intensity or/and 75 minutes of vigorous-intensity aerobic activity/week with those who did not. In addition, we evaluated this by categories of LTPA in quartiles of METs. We used conditional and unconditional logistic regression models to estimate the adjusted Odds Ratio(OR) of LTPA with overall breast cancer and by hormone receptor-positive and triple-negative breast cancer. Results The mean ages of cases and controls were similar after matching, $42.5 \pm 10.1$ and $41.5 \pm 9.2$ years (mean \pm SD), respectively. Women who attained the WHO PA recommendations had a $42 \%$ reduction in the odds of having breast cancer(OR=0.58 95\% Cl:0.43-0.78) compared with those who did not. LTPA was associated with reduced odds of having hormone receptor-positive by $41 \%$ and significantly associated with reduced odds of having triple-negative breast cancer by $45 \%$. In addition, a significant dose-response relationship was observed, women with higher levels of LTPA had lower odds of having overall breast cancer as well as having triple-negative and hormone receptor-positive breast cancer. Conclusions Increasing LTPA in African women can play a significant role in reducing the incidence of breast cancer, particularly of the more aggressive subtype as triple-negative, which is more prevalent in Sub-Saharan Africa.

\section{Background}

The incidence of breast cancer in Sub-Saharan Africa is rising, and it is now the commonest cancer in women in most countries in this area (1). In Nigeria, which constitutes nearly $52 \%$ of the population of West Africa, breast cancer incidence increased by approximately $25 \%$ per decade from estimated agestandardized incidence rate (ASR) of 13.7 per 100,000 in 1960-1969 to ASR of 41.7 per 100,000 in 2018 (2-4). In 2018, the amount of newly diagnosed breast cancers in Nigeria was estimated to be 26,310 which is $37.0 \%$ of all new cancers in Nigerian women and $15.6 \%$ of all new breast cancer cases in Africa (4).

Several factors are responsible for the rising rates of breast cancer in Sub-Saharan Africa. These include increased life expectancy thereby increasing the number of women growing into cancer-bearing old age, reduced risk of death from competing causes such as infections, social-economic development, lifestyle changes including delays in commencement of childbearing, reduced parity, and reduced duration of breastfeeding, obesity, and physical inactivity. (1, 5-9).

The prevalence of physical inactivity in Sub-Saharan Africa has risen in recent times as the population's transition from predominantly rural and agrarian to more developed urban, socio-economic systems (5). In Nigeria, more than $80 \%$ of urbanized adult women are physically inactive and do not meet the World health Organization (WHO) criteria for minimum levels for physical activity to maintain a healthy lifestyle and reduce the risks of chronic diseases (AkaroloAnthony \& Adebamowo, 2014). Physical inactivity lifestyle may place African women at a higher risk of breast cancer (10-13).

Physical inactivity may be associated with an increased risk of breast cancer through several biological mechanisms. Women with high levels of leisure-time physical activity (LTPA) have lower serum estradiol and higher sex hormone-binding globulin levels after adjusting for obesity and this association is more pronounce in post-menopausal compared to pre-menopausal breast cancer $(14,15)$. Exercise may influence breast cancer risk by inducing systemic antiinflammatory effect and other effects that may be mediated through the reduced visceral fat mass. (15-17).

Whereas acute physical activity is associated with oxidative stress, human adaptation to repeated exercise leads to the development of protective anti-oxidant effect associated with reduced cancer progression and metastasis $(15,18)$. In addition, physical activity reduces circulating leptin and insulin levels, and insulin resistance while increasing adiponectin, IGFBP-1 and IGFBP-3 levels (19-21). These influence the associations between the insulin pathway and breast cancer development and progression $(11,16,17,22-25)$.

Recent studies show that physical inactivity is associated with breast cancer and its various subtypes based on the hormone receptor and human epidermal growth factor-2 status (26-28). However, there has been no previous study of these relations in African women, particularly with triple-negative breast cancer that occurs more frequently in Sub-Saharan Africa compared to developed countries (29-31). Since physical inactivity is one of the potentially modifiable breast cancer risk factors, studies of its prevalence and association with breast cancer are likely to be informative and contribute to public policy on breast cancer prevention. Therefore, to fill this need, we examined associations between LTPA and total as well as molecular subtypes of breast cancer of hormone receptor-positive and triple-negative in Nigerian women. In addition, we examined whether Nigerian women who follow the LTPA recommendations of the WHO bore a significantly lower risk for overall and molecular subtypes of hormone receptor-positive and triple-negative breast cancer.

\section{Methods}

\section{Study design and setting}

We studied women enrolled in the Nigerian Integrative Epidemiology of Breast Cancer (NIBBLE) Study, a case-control study of female breast cancer that recruited participants at six government hospitals in Nigeria, five of whom are located in Abuja (National Hospital, University of Abuja Teaching Hospital Gwagwalada, Asokoro District Hospital, Garki Hospital and Wuse General Hospital) and the sixth hospital, the University of Nigeria Teaching Hospital, in Enugu, between January 2014 and July 2016. The details about the study design and setting have been previously published (2). 


\section{Participants}

Overall, 831 newly diagnosed patients with primary invasive breast cancer aged 18 years and above were identified at their first visit to the clinical sites. Research nurses informed potential participants about the study and obtained their informed consent. Age-matched hospital-based controls (996) were women who did not have cancer or endocrine diseases and were within \pm 2.5 year of the age of specific patients enrolled within one month in the same hospital. Predominantly, $>94.0 \%$ of women approached consented to participate. Research nurses conducted face-to-face interviews in the English language (70.6\%) or local Nigerian language $(29.4 \%)$ according to the patient's preference.

\section{Primary exposure}

For the LTPA assessment, we used a modification of the U.S. Nurses' Health Study (NHS) II physical activity questionnaire. The questionnaire measures the average amount of time spent per week on moderate and vigorous leisure-time activities. Participants reported the average time per week spent on each of the following moderate or vigorous activities, in the past year: walking, hiking, jogging, running, bicycling, dancing, playing tennis, soccer, squash; golf, swimming, aerobics, weight lifting or resistance exercise. We calculated participants' metabolic equivalents (METs) - hour/week of total LTPA by multiplying the number of hours per week of each activity with its corresponding MET values and then summarized all the MET values (32). We excluded one participant with an extreme value of MET. The final MET score was used to create two categories of participants: 'Leisure-time physical activity'-participants who met the WHO PA recommendations of at least 150 minutes of moderate-intensity or 75 minutes of vigorous-intensity aerobic LTPA, or an equivalent combination, and 'Leisure-time physical inactivity' - for those who did not meet the WHO PA recommendations (33). In addition, we created categories of LTPA in quartiles of METs $(<2.99,2.99-5.80,5.81-11.25,>11.25)$ based on the distribution of the study sample.

\section{Breast cancer and breast cancer subtypes}

Needle core biopsies were performed using Bard Magnum Biopsy Gun®. Breast specimens were fixed in $10 \%$ neutral buffered formalin and processed within 48 hours of fixation with a minimum fixation time of 8 hours in Leica ${ }^{\circledR}$ automatic tissue processors.

\section{Histology}

Sections of Paraffin-embedded blocks were cut at 3-4 $\mu \mathrm{m}$ and stained routinely with hematoxylin and eosin stains. Histological features were classified adopting 2003 WHO classification of breast diseases and graded using the Nottingham modification of the Bloom-Richardson grading (34).

\section{Immunohistochemistry (IHC)}

Histologically confirmed invasive breast tumors were stained by immunohistochemical techniques using the Thermo Scientific Lab Vision primary antibodies (clones ER-SP1; PR-SP2; Her2-SP3) and Thermo Scientific ${ }^{\text {TM }}$ Ultra Vision ${ }^{\text {TM }}$ Quanto HRP DAB detection kit according to manufacturer's recommended protocol (Petrosyan et al., 2002). In brief, formalin-fixed paraffin-embedded (FFPE) tissues were sectioned serially into $4 \mu \mathrm{m}$ and were placed in histogrip coated microscope slides and incubated overnight at $60 \mathrm{C}$, deparaffinized in series of xylene (three changes), graded alcohol ( $2 \mathrm{changes} 100 \%, 90 \%$, and $70 \%$ ethanol) and rehydrated in distilled water. Antigen retrieval was performed using a microwave at a level in $10 \mathrm{mM}$ citrate buffer ( $\mathrm{pH} 6.0$ ) at $95^{\circ} \mathrm{C}$ for 45 min. Sections were then washed with Phosphate Buffered Saline (PBS) and blocked with hydrogen peroxide for 10 minutes. Then Ultra $\mathrm{V}$ was applied to block nonspecific backgrounds staining for 5 minutes. At this stage, sections were washed with PBS, and primary antibodies (ER-SP1; PR-SP2; Her2-SP3) were applied on the sections and incubated at room temperature for 1 hour followed by application of primary antibody enhancer and HRP polymer. Staining was visualized using Diaminobenzidine (DAB) and counterstained with haematoxylin. Sections were dehydrated and cover slipped.

\section{IHC interpretation}

We obtained results of estrogen (ER), progesterone (PR) and human epidermal growth factor-2 (HER2) status in about $40 \%$ of participants. ER and PR were considered positive if $\geq 1 \%$ nuclei of the tumor cells were stained as per the American Society College Oncology/College American Pathology (ASCO/CAP) guidelines (35). HER2 staining was scored as $0,1+, 2+$, or $3+$ a positive HER2 result is IHC staining of $3+$ (uniform, intense membrane staining of $>30 \%$ of invasive tumor cells, (36).

\section{Breast cancer subtypes}

Overall, $36 \%$ of the cases (301/831) had immunohistochemistry tests that included results of estrogen, progesterone and human epidermal growth factor 2. We classified breast cancer subtypes using combinations of the IHC markers as follows (a) hormone receptor positive (estrogen and progesterone) /HER2 negative (HP), and triple-negative tumors which lacked all 3 markers (TNBC) (37). Therefore, among those cases: 34.0\% ( $n=103 / 301)$ were classified as HP, and $47.8 \%(n=144 / 301)$ as TNBC to further analysis subtypes of breast cancer.

\section{Covariates}

We collected information on age in years, levels of education (elementary, completed high school, post-high school with no university degree, completed university), marital status (married, single, separated/divorced/widowed), smoking experience (yes vs. no), alcohol use (yes vs. no), age at menarche, number of pregnancies $(0,1-3,4-6, \geq 7)$, ever use of oral contraceptive (yes vs. no), menopausal status (premenopausal vs. postmenopausal), age at menopause in years and breastfeeding experience of more than one month (yes vs. no). Research nurses measured participant's height, weight, waist, and hip circumferences and we derived body mass index $\left(\mathrm{BMI} \mathrm{kg} / \mathrm{m}^{2}\right.$ ) and waist-hip ratio (WHR) from these measurements. Participants with extreme values of WHR of less than 0.7 or higher than 1.6 and with a BMl less than $10 \mathrm{~kg} / \mathrm{m}^{2}$ or greater than $50 \mathrm{~kg} / \mathrm{m}^{2}$ were excluded from the analyses (38). To compute socioeconomic status, we calculated the 'wealth index' using the following variables - house ownership and type of house owned (e.g. home, apartment, house or 
duplex); source of drinking water (e.g. from outside, well, borehole, piped or bottled); type of cooking fuel; use of separate room for cooking; type of toilet; and ownership of household goods including car and refrigerator. We used Principal Component Analysis (PCA) with varimax rotation to compute factor scores based on the sum of responses to these variables weighted by their factor loading. We used the first component in the PCA that explained most of the variations in the data, to generate a wealth index (39). The wealth index variable was used to classify participants to inferior socio-economic status (lowest $40 \%$ of the score distribution), middle (middle $40 \%$ ) and high (highest $20 \%$ ) socio-economic class.

\section{Statistical Analysis}

From the initial study sample (1,827), the following variables included missing values: marital status (1.8\%), education (2.0\%), menopausal status (2.5\%), pregnancy (2.8\%) wealth index (2.9\%), LTPA (7.8\%), BMI (4.1\%), WHR (4.2\%), smoking (2.5\%), alcohol (2.5\%) and occupation (4.8\%), age at the first menstrual period $(6.9 \%)$, use of contraceptives $(2.7 \%)$ and breastfeeding experience $(4.1 \%)$. We excluded women with missing values, which reduced the sample size to 1,444 . Subsequently, of those, 630 cases were matched with 630 controls based on age ( \pm 5 year) using propensity score with the optimal matching procedure.

\section{Overall breast cancer}

To examine bivariate associations between independent variables, primary exposure (LTPA) by cases and control, we implemented conditional logistic regressions. Then, for the multivariable models, we selected the independent variables that examined differences between cases and controls $p$-value $<0.20$ in the bivariate analysis. Significantly, alcohol use that has been associated with breast cancer in previous publications was included in our multivariable models as well. In the multivariable odds ratios, we conducted conditional logistic regression models employing Wald tests to identify covariates with the significant association ( $p$-value $<0.05$ ) with overall breast cancer risk and to examine our main study hypothesis.

\section{Breast cancer subtypes}

To examine associations between LTPA and breast cancer subtypes, we used from the initial sample, subsamples of HP cases ( $n=103$ ), and of TNBC ( $n=144$ ) vs. controls ( $n=996)$ and applied unconditional logistic regression models to assess age-adjusted and multivariable odds ratios for each subtype separately.

All analyses were performed using Stata SE version 15.1 (College Station, Texas) and R-Studio Version 1.1.447.

\section{Results}

The characteristics of cases and controls are described in Table 1. Women with breast cancer were older, attained menopause at an older age, retained lower levels of education, and held more non-professional jobs compared to women in the control group. However, the two groups were similar with regards to socioeconomic status, marital status, and number of pregnancies, breastfeeding experience, and alcohol use. The mean BMI and WHR were moderately higher among controls than cases. Women in the control groups (30.0\%) were more likely to be physically active compared to those in the case group (18.1\%). A similar trend was found in the highest levels of LTPA where a higher proportion of women in the control group performed more than 5.8 METs of LTPA per week than the case group.

Table 2 shows the results of the multivariable conditional logistic regression models. Based on the final models, there was a significant association between LTPA and overall breast cancer risk. Specifically, women who met the WHO recommendation for LTPA demonstrated a significant reduction of $42 \%$ in the odds of having breast cancer compared to women who did not (OR $=0.58,95 \% \mathrm{Cl}$ : $0.43-0.78$; $p$-value< 0.001$)$ after controlling for significant covariates.

Furthermore, women who had more than 11.25 METs hour per week of LTPA had $55 \%$ reduction in odds of having breast cancer compared to women who had less than 2.99 METs per week $\left(\mathrm{OR}_{1}\right.$ vs.4 $=0.45,95 \% \mathrm{Cl}: 0.31-0.65 ; p$-value< 0.001$)$.

In table 3, we show the results of the analyses of LTPA and molecular subtypes of breast cancer. We compared women in extreme quartiles of LTPA and found significantly lower odds of having hormone receptor-positive breast cancer $\left(\mathrm{OR}_{1 \mathrm{vs} .4}=0.42,95 \% \mathrm{Cl}: 0.21-0.83\right)$ and triple-negative breast cancer $\left(\mathrm{OR}_{1 \mathrm{vs} .4}=0.34\right.$ $95 \% \mathrm{Cl}: 0.19$ - 0.63). Ultimately, women who met the WHO recommendation for LTPA showed a $41 \%$ reduction in the odds of having hormone receptor-positive and $45 \%$ reduction in the odds of having triple-negative breast cancer.

\section{Discussion}

In this study, we showed that LTPA is associated with a reduction in the odds of having overall breast cancer and having triple-negative and hormone receptorpositive breast cancer among Nigerian women. Our results are consistent with findings from other breast cancer studies in African women (10, 12). For example, a multi-country case-control study of women from Nigeria, Cameroon, and Uganda who completed a culturally tailored physical activity, questionnaires showed a significant reduction in breast cancer risk of up to 60\%, with a dose-response relationship (Hou et al., 2014).

Our finding of association between LTPA and molecular subtypes of hormone receptor-positive and triple-negative breast cancer is the first in African women and similar to findings in other populations $(13,17,26-28,40,41)$. For example, a multi-center population-based case-control study of young women in the United States experienced a $27 \%$ reduction in risk of triple-negative breast cancer (42). Another study utilizing data from the Women's Health Initiative examined the baseline recreational physical activity and the risk of breast cancer subtypes, eight years later. Women in the highest activity category demonstrated $23 \%$ more reduced risk of triple-negative and $15 \%$ lower risk of estrogen receptor-positive breast cancer compared with women who reported no recreational physical activity (Phipps et al., 2011.).

In the current study, majority of the breast cancer cases and controls did not meet the WHO recommendation for minimum levels of physical activity, and this is similar to the findings from another study of LTPA among urbanized Nigerians (Akarolo-Anthony \& Adebamowo, 2014). Compared with the global average,

Page $4 / 10$ 
where only 1 in 4 adults do not meet the WHO recommendation, the prevalence of physical inactivity in urbanized Nigerian women is significantly high (43). Furthermore, the median activity level in our study sample was 5.8 MET-hours/week overall, which is lower than the median activity level of 8.0 MET-

hours/week found in cancer cohort studies in the US and Europe (13).

In this study, among the approximately $20 \%$ of participants who were physically active, the most frequent physical activities were dancing, walking and hiking (data not shown). This is similar to the findings of other studies in Nigeria (5) which showed that dancing contributed the highest MET-hours/week for LTPA among adult Nigerian women, followed by walking, hiking and jogging. In Nigeria, dancing most frequently occurred during religious observances, therefore intervention programs to encourage uptake of physical activity should consider approaches that enhances and promotes current, culturally relevant practices (5).

Numerous case-control and cohort studies suggest there is an overall average of $20-25 \%$ risk reduction for breast cancer-associated directly with increased physical activity $(7,8,44,45)$. Although our study findings replicate these previous studies, the potential risk reduction in our population is higher up to $55 \%$ after controlling for BMI, WHR, alcohol use, fertility covariates, and sociodemographic factors, possibly because of the current extreme levels of physical inactivity in Nigerian women. Although the incidence of breast cancer in Nigeria is currently lower than in high-income countries, reduction in incidence may be attained by increasing uptake of LTPA in this population.

The limitations of our study include recall bias, the potential impact of breast cancer on levels of LTPA and the use of a self-reported questionnaire (46). Previous studies of LTPA in Nigerian women without breast cancer, however, showed similar results to our study (Akarolo-Anthony \& Adebamowo, 2014). We did not adjust for family history of breast cancer, but previous studies showed a low prevalence of this risk factor in Nigerian breast cancer patients. We also did not adjust for foods and nutrients intakes, but we adjusted for BMI, WHR and for alcohol intakes, the dietary factor most consistently associated with breast cancer risk.

Despite these limitations, the strengths of our study include histological and immunohistochemical confirmation of molecular subtypes, a large sample size with sufficient power to detect significant results, inclusion of a broad range of well-established covariates and confounders such as BMI, menopausal status, demographic variables, types of occupation, as well as relative homogeneity of the study population $(10,27,47)$.

\section{Conclusions}

In low- and middle-income countries where the incidence of breast cancer is rising, increased uptake of LTPA can significantly reduce the incidence of breast cancer, particularly of the more aggressive subtype as triple-negative breast cancer which is more prevalent in women in Sub-Saharan Africa.

\section{Abbreviations}

ASR, Age-Standardized incidence Rate

WHO, World Health Organization

PA, Physical Activity

LTPA, Leisure-Time Physical Activity

METs, Metabolic Equivalents

OR, Odds Ratio

NIBBLE, Nigerian Integrative Epidemiology of Breast Cancer

NHS, Nurses' Health Study

IHC, Immunohistochemistry

TNBC, Triple-Negative Breast Cancer

HP, Hormone Receptor Positive Breast Cancer

HER2, Human Epidermal Growth Factor 2

ER, Estrogen Receptor

PR, Progesterone Receptor

BMI, Body Mass Index

WHR, Waist-Hip Ratio

$\mathrm{Cl}$, Confidence Interval

PCA, Principal Component Analysis 


\section{Declarations}

\section{Ethical approval and consent to participate}

Ethical approval was obtained from the National Health Research Ethics Committee of Nigeria, Health Research Ethics Committees in each participating hospital and the institutional ethics committees at the University of Maryland School of Medicine, Baltimore (US) and the London School of Hygiene and Tropical Medicine (UK). The study was carried out in compliance with the Nigerian National Code for Health Research Ethics. All participants gave written informed consent in accordance with the Declaration of Helsinki and the Nigerian National Code for Health Research Ethics.

\section{Consent for publication}

Not applicable

\section{Availability of data and materials}

The datasets used and/or analysed during the current study are available from the corresponding author on reasonable request.

\section{Competing interests}

The authors declare that they have no competing interests.

\section{Funding}

The project described was supported by the Training Program in Nigeria for Non-communicable Diseases Research (TRAPING NCD) grant number FIC/NIH D43TW009106 from the Fogarty International Centre; by the Maryland Department of Health and Mental Hygiene award Number: Cigarette Restitution Fund; and by the National Cancer Institute award Number: 5P30CA134274. The funding agencies did not play any role in data collection, analysis or publication.

\section{Authors' Contributions}

GB had the idea for the study, conducted the data analysis, and drafted the manuscript and made subsequent revisions to the manuscript; TY, MY, OO, OB, EE, IS, EM, IA, and BA contributed to data collection, data quality and approved the final draft; AF contributed to the description of the materials and methods; EA contributed to manuscript revision; SA contributed to the study design, data quality, data analysis, and manuscript revision; CA had the idea for the study design, obtained funding, supervised data analyses and provided critical revisions to the manuscript. All authors read and approved the final draft.

\section{Acknowledgments}

The project described was supported by the Training Program in Nigeria for Non-communicable Diseases Research (TRAPING NCD) grant number FIC/NIH D43TW009106 from the Fogarty International Centre. The content is solely the responsibility of the authors and does not necessarily represent the official views of the Fogarty International Centre or the National Institutes of Health.

\section{References}

1. Bray F, Ferlay J, Soerjomataram I, Siegel RL, Torre LA, Jemal A. Global cancer statistics 2018: GLOBOCAN estimates of incidence and mortality worldwide for 36 cancers in 185 countries. CA Cancer J Clin. 2018;68(6):394-424.

2. Jedy-Agba E, McCormack V, Olaomi O, Badejo W, Yilkudi M, Yawe T, et al. Determinants of stage at diagnosis of breast cancer in Nigerian women: sociodemographic, breast cancer awareness, health care access and clinical factors. Cancer Causes Control. 2017;28(7):685-97.

3. Jedy-Agba E, Curado MP, Ogunbiyi O, Oga E, Fabowale T, Igbinoba F, et al. Cancer incidence in Nigeria: a report from population-based cancer registries. Cancer Epidemiol. 2012;36(5):e271-8.

4. Cancer IAfRo. Estimated number of new cases in 2018, Africa, Nigeria, females, all ages 2018 [Available from: http://gco.iarc.fr/today/online-analysistable? v=2018\&mode=cancer\&mode_population=continents\&population=900\&populations=903_566\&key=asr\&sex=2\&cancer=39\&type=0\&statistic=5\&prevalenc by_country.

5. Akarolo-Anthony SN, Adebamowo CA. Prevalence and correlates of leisure-time physical activity among Nigerians. BMC Public Health. 2014;14:529.

6. Brinton LA, Figueroa JD, Awuah B, Yarney J, Wiafe S, Wood SN, et al. Breast cancer in Sub-Saharan Africa: opportunities for prevention. Breast Cancer Res Treat. 2014;144(3):467-78.

7. Friedenreich CM. The role of physical activity in breast cancer etiology. Semin Oncol. 2010;37(3):297-302.

8. Monninkhof EM, Elias SG, Vlems FA, van der Tweel I, Schuit AJ, Voskuil DW, et al. Physical activity and breast cancer: a systematic review. Epidemiology. 2007;18(1):137-57.

9. Parkin DM, Bray F, Ferlay J, Jemal A. Cancer in Africa 2012. Cancer Epidemiol Biomarkers Prev. 2014;23(6):953-66.

10. Hou N, Ndom P, Jombwe J, Ogundiran T, Ademola A, Morhason-Bello I, et al. An epidemiologic investigation of physical activity and breast cancer risk in Africa. Cancer Epidemiol Biomarkers Prev. 2014;23(12):2748-56.

11. Wu Y, Zhang D, Kang S. Physical activity and risk of breast cancer: a meta-analysis of prospective studies. Breast Cancer Res Treat. 2013;137(3):869-82.

12. Awatef M, Olfa G, Rim C, Asma K, Kacem M, Makram H, et al. Physical activity reduces breast cancer risk: a case-control study in Tunisia. Cancer Epidemiol. 2011;35(6):540-4 
13. Moore SC, Lee IM, Weiderpass E, Campbell PT, Sampson JN, Kitahara CM, et al. Association of Leisure-Time Physical Activity With Risk of 26 Types of Cancer in 1.44 Million Adults. JAMA Intern Med. 2016;176(6):816-25.

14. Friedenreich CM. Physical activity and breast cancer risk: the effect of menopausal status. Exercise and sport sciences reviews. 2004;32(4):180-4.

15. de Boer MC, Worner EA, Verlaan D, van Leeuwen PAM. The Mechanisms and Effects of Physical Activity on Breast Cancer. Clin Breast Cancer. 2017;17(4):272-8.

16. McTiernan A, Wu L, Chen C, Chlebowski R, Mossavar-Rahmani Y, Modugno F, et al. Relation of BMI and physical activity to sex hormones in postmenopausal women. Obesity (Silver Spring). 2006;14(9):1662-77.

17. Phipps Al, Chlebowski RT, Prentice R, McTiernan A, Stefanick ML, Wactawski-Wende J, et al. Body size, physical activity, and risk of triple-negative and estrogen receptor-positive breast cancer. Cancer Epidemiol Biomarkers Prev. 2011;20(3):454-63.

18. Yeo S, Davidge ST. Possible beneficial effect of exercise, by reducing oxidative stress, on the incidence of preeclampsia. Journal of women's health \& gender-based medicine. 2001;10(10):983-9.

19. Gleeson M, Bishop NC, Stensel DJ, Lindley MR, Mastana SS, Nimmo MA. The anti-inflammatory effects of exercise: mechanisms and implications for the prevention and treatment of disease. Nature reviews Immunology. 2011;11(9):607-15.

20. Tworoger SS, Eliassen AH, Kelesidis T, Colditz GA, Willett WC, Mantzoros CS, et al. Plasma Adiponectin Concentrations and Risk of Incident Breast Cancer. The Journal of Clinical Endocrinology \& Metabolism. 2007;92(4):1510-6.

21. Harris HR, Tworoger SS, Hankinson SE, Rosner BA, Michels KB. Plasma Leptin Levels and Risk of Breast Cancer in Premenopausal Women. Cancer Prev Res (Phila). 2011;4(9):1449-56.

22. Wolf I, Rubinek T. Diabetes Mellitus and Breast Cancer.

23. Neil-Sztramko SE, Boyle T, Milosevic E, Nugent SF, Gotay CC, Campbell KL. Does obesity modify the relationship between physical activity and breast cancer risk? Breast Cancer Res Treat. 2017;166(2):367-81.

24. McTiernan A. Mechanisms linking physical activity with cancer. Nat Rev Cancer. 2008;8(3):205-11.

25. Hans-Olov Adami DJH, Pagona Lagiou, and Lorelei Mucci. Textbook of CANCER EPIDEMIOLOGY Third edition: OXFORD university press; 2018.

26. Lope V, Martin M, Castello A, Casla S, Ruiz A, Baena-Canada JM, et al. Physical activity and breast cancer risk by pathological subtype. Gynecol Oncol. 2017;144(3):577-85.

27. Park B, Choi JY, Sung HK, Ahn C, Hwang Y, Jang J, et al. Attribution to Heterogeneous Risk Factors for Breast Cancer Subtypes Based on Hormone Receptor and Human Epidermal Growth Factor 2 Receptor Expression in Korea. Medicine (Baltimore). 2016;95(14):e3063.

28. Steindorf K, Ritte R, Eomois PP, Lukanova A, Tjonneland A, Johnsen NF, et al. Physical activity and risk of breast cancer overall and by hormone receptor status: the European prospective investigation into cancer and nutrition. International journal of cancer. 2013;132(7):1667-78.

29. Huo D, Ikpatt F, Khramtsov A, Dangou JM, Nanda R, Dignam J, et al. Population differences in breast cancer: survey in indigenous African women reveals over-representation of triple-negative breast cancer. J Clin Oncol. 2009;27(27):4515-21.

30. Wright N, Rida P, Rakha E, Agboola A, Aneja R. Panoptic Overview of Triple-Negative Breast Cancer in Nigeria: Current Challenges and Promising Global Initiatives. J Glob Oncol. 2018(4):1-20.

31. Zheng Y, Walsh T, Gulsuner S, Casadei S, Lee MK, Ogundiran TO, et al. Inherited Breast Cancer in Nigerian Women. J Clin Oncol. 2018;36(28):2820-5.

32. Ainsworth BE, Haskell WL, Whitt MC, Irwin ML, Swartz AM, Strath SJ, et al. Compendium of physical activities: an update of activity codes and MET intensities. Med Sci Sports Exerc. 2000;32(9 Suppl):S498-504.

33. WHO Guidelines Approved by the Guidelines Review Committee. Global Recommendations on Physical Activity for Health. Geneva: World Health Organization Copyright (c) World Health Organization 2010.; 2010.

34. Christgen M, Langer F, Kreipe H. [Histological grading of breast cancer]. Pathologe. 2016;37(4):328-36.

35. Hammond ME, Hayes, D.F., Dowsett, M., Allred, D.C., Hagerty, K.L., Badve, S., Fitzgibbons, P.L., Francis, G., Goldstein, N.S., Hayes, M., et al. Pathologists' Guideline Recommendations for Immunohistochemical Testing of Estrogen and Progesterone Receptors in Breast Cancer. Breast Care (Basel). 2010;5(3):185-7.

36. Wolff AC, Hammond ME, Schwartz JN, Hagerty KL, Allred DC, Cote RJ, et al. American Society of Clinical Oncology/College of American Pathologists guideline recommendations for human epidermal growth factor receptor 2 testing in breast cancer. Arch Pathol Lab Med. 2007;131(1):18-43.

37. Waks AG, Winer EP. Breast Cancer Treatment: A Review. JAMA. 2019;321(3):288-300.

38. Adebamowo CA, Ogundiran TO, Adenipekun AA, Oyesegun RA, Campbell OB, Akang EE, et al. Waist-hip ratio and breast cancer risk in urbanized Nigerian women. Breast Cancer Res. 2003;5(2):R18-24.

39. Filmer D, Pritchett LH. Estimating wealth effects without expenditure data-or tears: an application to educational enrollments in states of India. Demography. 2001;38(1):115-32.

40. Ellingjord-Dale M, Vos L, Hjerkind KV, Hjartaker A, Russnes HG, Tretli S, et al. Alcohol, Physical Activity, Smoking, and Breast Cancer Subtypes in a Large, Nested Case-Control Study from the Norwegian Breast Cancer Screening Program. Cancer Epidemiol Biomarkers Prev. 2017;26(12):1736-44.

41. Ma H, Xu X, Clague J, Lu Y, Togawa K, Wang SS, et al. Recreational physical activity and risk of triple negative breast cancer in the California Teachers Study. Breast Cancer Res. 2016;18(1):62.

42. Trivers KF, Lund MJ, Porter PL, Liff JM, Flagg EW, Coates RJ, et al. The epidemiology of triple-negative breast cancer, including race. Cancer Causes Control. 2009;20(7):1071-82.

43. WHO. World Health Organization 2018 [Available from: https://apps.who.int/iris/bitstream/handle/10665/272722/9789241514187-eng.pdf.

Page 7/10 
44. Kruk J. Lifetime physical activity and the risk of breast cancer: a case-control study. Cancer Detect Prev. 2007;31(1):18-28.

45. Lynch BM, Neilson HK, Friedenreich CM. Physical activity and breast cancer prevention. Recent Results Cancer Res. 2011;186:13-42.

46. Dallal CM, Brinton LA, Matthews CE, Lissowska J, Peplonska B, Hartman TJ, et al. Accelerometer-based measures of active and sedentary behavior in relation to breast cancer risk. Breast Cancer Res Treat. 2012;134(3):1279-90.

47. Kakugawa Y, Tada H, Kawai M, Suzuki T, Nishino Y, Kanemura S, et al. Associations of obesity and physical activity with serum and intratumoral sex steroid hormone levels among postmenopausal women with breast cancer: analysis of paired serum and tumor tissue samples. Breast Cancer Res Treat. 2017;162(1):115-25.

\section{Tables}


Table 1

Descriptive characteristics of the study population, the Nigerian Integrative Epidemiology of Breast Cancer Study (NIBBLE), the year $2014-2016$.

\begin{tabular}{|c|c|c|c|}
\hline & $\begin{array}{c}\text { Cases }^{{ }^{\mathrm{a}}} \\
\text { Mean } \pm \mathrm{SD} / \mathrm{N}(\%) \\
\mathrm{N}=630\end{array}$ & $\begin{array}{c}\text { Control }^{\text {a }} \\
\text { Mean } \pm \text { SD /N(\%) } \\
\mathrm{N}=630\end{array}$ & $p$-value ${ }^{a}$ \\
\hline Age, years & $42.5 \pm 10.1$ & $41.5 \pm 9.2$ & $0.096^{+}$ \\
\hline Age at first menstrual period, years & $14.3 \pm 1.7$ & $14.4 \pm 1.9$ & 0.179 \\
\hline $\mathrm{BMI} \mathrm{kg} / \mathrm{m}^{2}$ & $28.1(5.8)$ & $28.8(5.8)$ & 0.025 \\
\hline WHR & $1.14(0.1)$ & $1.16(0.1)$ & $<0.001$ \\
\hline Education & & & 0.378 \\
\hline Elementary $<=$ & $131(20.8)$ & $112(17.8)$ & \\
\hline Complete HS & $141(22.4)$ & $165(26.2)$ & \\
\hline Post HS no university & $174(27.6)$ & $149(23.7)$ & \\
\hline Completed University & $184(29.2)$ & $204(33.3)$ & \\
\hline Marital status & & & 0.863 \\
\hline Married & $453(71.9)$ & $450(71.4)$ & \\
\hline Single & $97(15.4)$ & 99 (15.7) & \\
\hline Separated/Divorced/Widowed & $80(12.7)$ & $81(12.9)$ & \\
\hline Occupation & & & $<0.001$ \\
\hline Self-employed & $169(26.8)$ & 73 (11.6) & \\
\hline Unskilled manual & $263(41.8)$ & $351(55.7)$ & \\
\hline Skilled manual & $158(25.1)$ & 109 (17.3) & \\
\hline Professional/executive & $40(6.3)$ & $97(15.4)$ & \\
\hline Wealth index & & & 0.155 \\
\hline Low & $223(35.4)$ & $257(40.8)$ & \\
\hline Middle & $296(47.0)$ & $265(42.1)$ & \\
\hline High & $111(17.6)$ & $108(17.1)$ & \\
\hline Ever used oral contraceptives & & & 0.065 \\
\hline No & $453(72.0)$ & $419(66.8)$ & \\
\hline Yes & $177(28.0)$ & $211(33.2)$ & \\
\hline Number of pregnancies & & & 0.080 \\
\hline 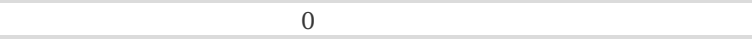 & $90(14.3)$ & $81(12.9)$ & \\
\hline $1-3$ & $138(21.9)$ & $118(18.7)$ & \\
\hline $4-6$ & $288(45.7)$ & $305(48.4)$ & \\
\hline$\geq 7$ & $114(18.1)$ & $126(20.0)$ & \\
\hline Menopausal status & & & 0.022 \\
\hline Premenopausal & 449 (71.3) & $475(75.4)$ & \\
\hline Postmenopausal & $181(28.7)$ & $155(24.6)$ & \\
\hline Ever breastfed more than one month & & & 0.060 \\
\hline No & $154(24.4)$ & $129(20.5)$ & \\
\hline Yes & $476(75.6)$ & $501(79.5)$ & \\
\hline Smoke & & & 0.178 \\
\hline No & $627(99.7)$ & $624(99.0)$ & \\
\hline Yes & $3(0.3)$ & $6(1.0)$ & \\
\hline Alcohol use & & & 0.558 \\
\hline No & 499 (79.3) & $508(80.7)$ & \\
\hline Yes & $131(20.7)$ & $122(19.3)$ & \\
\hline Leisure-time physical activity (meet the WHO recommendations) & & & $<0.001$ \\
\hline Physical active & $114(18.1)$ & $189(30.0)$ & \\
\hline Physical inactive & $516(81.9)$ & $441(70.0)$ & \\
\hline Leisure-time physical activity by MET h/w & & & $<0.001$ \\
\hline$<2.99$ & $197(31.3)$ & $107(17.0)$ & \\
\hline $2.99-5.80$ & $164(26.0)$ & $156(24.8)$ & \\
\hline $5.81-11.25$ & $150(23.8)$ & $181(28.7)$ & \\
\hline $11.25<$ & $119(18.9)$ & $186(29.5)$ & \\
\hline
\end{tabular}

Cases and controls are matched by age $( \pm 5$ years $)$

${ }^{+}$t-test

BMI, Body Mass Index; WHR, Waist-Hip Ratio; MET, Metabolic Equivalent; SD, standard deviation; N, number of subjects; HS, High School; WHO, World Health Organization 
Table 2.

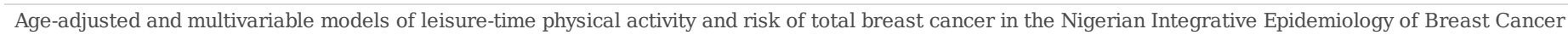
Study (NIBBLE), the year 2014-2016

\begin{tabular}{|c|c|c|c|c|}
\hline \multirow[b]{3}{*}{$\begin{array}{l}\text { Leisure-time physical activity }{ }^{\mathrm{d}} \\
\text { (meet the WHO recommendations) }\end{array}$} & \multicolumn{2}{|c|}{ Age-adjusted model $^{\text {a }}$} & \multicolumn{2}{|c|}{ Multivariable model a b } \\
\hline & OR $(95 \% \mathrm{CI})$ & P-value & b OR (95\% CI) & P-value \\
\hline & $0.52(0.39-0.68)$ & $<0.001$ & $0.58(0.43-0.78)$ & $<0.001$ \\
\hline Leisure-time physical activity by MET h/w ${ }^{\mathrm{e}}$ & & $<0.001^{\mathrm{c}}$ & & $<0.001^{\mathrm{c}}$ \\
\hline $2.99-5.80$ & $0.57(0.41-0.79)$ & 0.001 & $0.69(0.47-0.99)$ & 0.044 \\
\hline $5.81-11.25$ & $0.44(0.32-0.62)$ & $<0.001$ & $0.50(0.35-0.73)$ & $<0.001$ \\
\hline $11.25<$ & $0.35(0.25-0.49)$ & $<0.001$ & $0.45(0.31-0.65)$ & $<0.001$ \\
\hline
\end{tabular}

Cases and controls were matched by age ( \pm 5 years) analyses were done using a conditional logistic regression model.

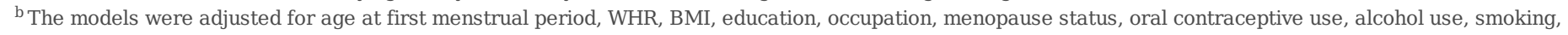
breastfeeding experience, Wealth index.

${ }^{\mathrm{c}}$ P-trend

${ }^{\mathrm{d}}$ Reference category- leisure-time physical inactive, did not meet the WHO recommendations for physical activity

${ }^{e}$ Reference category- leisure-time physical activity of less than $2.99 \mathrm{MET} \mathrm{h} / \mathrm{w}$

BMI, Body Mass Index; WHR, Waist-Hip Ratio; MET, Metabolic Equivalent, OR, Odds Ratio; CI, Confidence Interval; h, hour; w, week

Table 3

Age-adjusted and multivariable models of leisure-time physical activity and risk of breast cancer subtypes (HP, TNBC) in the Nigerian Integrative Epidemiology of Breast Cancer Study (NIBBLE), the year 2014-2016.

\begin{tabular}{|c|c|c|c|c|}
\hline & \multicolumn{2}{|c|}{ HP $(\mathrm{ER}+/ \mathrm{PR}+) / \mathrm{HER} 2-$} & \multicolumn{2}{|c|}{ TNBC } \\
\hline & $\begin{array}{c}\text { Age-Adjusted model a } \\
\text { OR } \\
(95 \% \mathrm{CI})\end{array}$ & $\begin{array}{c}\text { Multivariable Model a b } \\
\text { OR } \\
(95 \% \text { CI })\end{array}$ & $\begin{array}{c}\text { Age-Adjusted model }^{\mathrm{a}} \\
\text { OR } \\
(95 \% \mathrm{CI})\end{array}$ & $\begin{array}{c}\text { Multivariable Model a b }^{\text {OR }} \\
(95 \% \mathrm{CI})\end{array}$ \\
\hline $\begin{array}{l}\text { Leisure-time physical activity }{ }^{\mathrm{d}} \\
\text { (meet the WHO recommendations) }\end{array}$ & $\begin{array}{c}0.60 \\
(0.35-1.02)\end{array}$ & $\begin{array}{c}0.59 \\
(0.33-1.06)\end{array}$ & $\begin{array}{c}0.53 \\
(0.33-0.86)\end{array}$ & $\begin{array}{c}0.55 \\
(0.33-0.91)\end{array}$ \\
\hline$P$-value & 0.061 & 0.081 & 0.009 & 0.021 \\
\hline \multicolumn{5}{|c|}{ Leisure-time physical activity by MET h/w ${ }^{\mathrm{e}}$} \\
\hline $2.99-5.80$ & $\begin{array}{c}0.62 \\
(0.34-1.11)\end{array}$ & $\begin{array}{c}0.65 \\
(0.34-1.22)\end{array}$ & $\begin{array}{c}0.50 \\
(0.30-0.83)\end{array}$ & $\begin{array}{c}0.59 \\
(0.34-1.03)\end{array}$ \\
\hline $5.81-11.25$ & $\begin{array}{c}0.55 \\
(0.30-0.99)\end{array}$ & $\begin{array}{c}0.60 \\
(0.32-1.11)\end{array}$ & $\begin{array}{c}0.45 \\
(0.27-0.74)\end{array}$ & $\begin{array}{c}0.53 \\
(0.31-0.90)\end{array}$ \\
\hline $11.25<$ & $\begin{array}{c}0.40 \\
(0.21-0.74)\end{array}$ & $\begin{array}{c}0.42 \\
(0.21-0.83)\end{array}$ & $\begin{array}{c}0.30 \\
(0.17-0.52)\end{array}$ & $\begin{array}{c}0.34 \\
(0.19-0.63)\end{array}$ \\
\hline$P$-trend ${ }^{\mathrm{c}}$ & 0.004 & 0.015 & $<0.001$ & 0.001 \\
\hline
\end{tabular}

${ }^{a}$ Unconditional logistic regression models with complete study sample

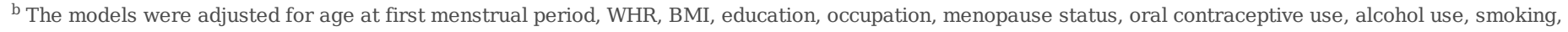
breastfeeding experience, Wealth index.

c $P$-trend

${ }^{\mathrm{d}}$ Reference category-leisure-time physical inactivity, did not meet the WHO recommendations for physical activity

${ }^{\text {e }}$ Reference category-leisure-time physical activity of less than 2.99 MET h/w

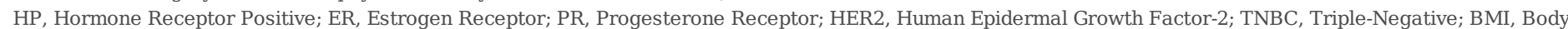
Mass Index; WHR, Waist-Hip Ratio; MET, Metabolic Equivalent, OR, Odds Ratio; CI, Confidence Interval; h, hour; w, week 